https://doi.org/10.15407/ujpe64.3.207

E.P. FELDMAN, N.A. KALUGINA, T.N. MELNIK

Institute for Physics of Mining Processes, Nat. Acad. of Sci. of Ukraine

(2-a, Simferopol'ska Str., Dnipro, Ukraine; e-mail: kalugina_n_a@ukr.net)

\title{
KINETIC THEORY OF THE FRACTURE OF THE COAL (ROCK) EDGE BY THE GAS-FILLED CRACKS. INSTANTANEOUS LOADING-OUT
}

\begin{abstract}
The kinetic theory of the fracture of brittle materials is applied to the study of undercritical and critical growths of cracks in gas-filled rocks. In this type of the materials, the gas filtration from the environment to the cavity of a growing crack plays an important role. The proper account for this factor combined with the dynamics of the stressed state of the bed allows the estimation of the rate of growth of the main crack on the assumption of the Griffith criterion validity. It is found that, immediately after the instantaneous loading-out of the bed in the course of excavation, the cracks of certain size and orientation are exploded with the succeeding growth dependent on the gas entry into the cracks. The time of the filtration growth of the cracks has been estimated. The intervals of the control parameters (formational gas pressure, crack size, overburden pressure, surface energy of coal/rock, modulus of elasticity), where the spontaneous fracture of the bed becomes possible, have been found. The results open a way to the forecast of instantaneous outbursts of coal, rock, and gas.

Ke ywords: coal bed, gas-filled crack, filtration, outburst.
\end{abstract}

\section{Introduction}

In a virgin fractured gas-saturated coal/rock bed, no fracture occurs, despite the bursting pressure of the gas filling the cavities of the cracks. The cracks are suppressed by the rock pressure. In the course of excavation, the edge of the bed is loaded-out of the stresses caused by the overburden pressure [1]. For the sake of definiteness, we consider a flat dip. In this case, vertical stresses, i.e., the overburden pressure itself, are redistributed and sharply increased near the face. The horizontal stresses normal to the edge surface vanish in a vicinity of the surface at a distance about the depth of the stratum. In other words, being present within the bed, the natural cracks parallel to the face surface are dispensed with the compressing overburden pressure. They tend to growth under the tensile stresses caused by the pressure of a gas

(C) E.P. FELDMAN, N.A. KALUGINA, T.N. MELNIK, 2019 ISSN 2071-0194. Ukr. J. Phys. 2019. Vol. 64, No. 3 contained by the cracks $[2,3]$. The flat tip cracks and the oblique ones, to certain extent, stay incapable of the growth. At the same time, they play an important role in the fracture of the selvage. They are the main transport channels that control the gas filtration from coal/rock to both the cavities of growing cracks and the mined-out space outside $[4,5]$. In turn, the rate of gas filtration determines the gas pressure in the growing cracks and the rate of growth as well. Because of the non-homogeneity of the overburden pressure, the bed permeability can vary over the bed course and vanish in a vicinity of the maximum of the abutment (overburden) pressure. As a result, a "plug" can be formed. This disables the gas release into the mined-out space and provides the start of the spontaneous fracture accompanied by the outburst of coal, rock, and gas [6]. The present work pays a substantial attention to the problem. In coal beds and wallrocks, a gas (methane, as a rule) is concentrated 
mostly in cracks and pores in the free form, but a part of methane molecules is dissolved in the coal matrix in the form of a solid solution [1]. The gas pressure in the crack cavities of a virgin bed (formation pressure) is several times smaller than the overburden pressure. In the course of excavation after the loading out, it is the gas pressure that initiates the fracture. The gas tends to burst the bed. The cohesion forces prevent the fracture. By Griffith [79 ], the rupture occurs when the coefficient of stress concentration at the tip of a crack (proportional to the stresses on the crack edges, i.e., in the considered case, the gas pressure) exceeds the modulus of cohesion of the coal/rock. It is known $[3,10,11]$ and clear due to simple physical contemplations that the evolution of cracks after the instantaneous loadingout includes a stage that should be called an impact one. The impact stage lasts for pro mille of a second: the crack swells up instantaneously because of the vanished compressing horizontal stresses that are about a half of the overburden pressure. At this stage, the role of the gas pressure is negligible, because it is small as compared to the overburden pressure, as mentioned above. An increase in the crack volume is totally due to an increment in the gap. It is determined by the loading-out, initial size of the crack, and elastic moduli of the matrix. The gas amount contained in the crack at the impact stage of the evolution remains the same because of a short duration of the stage. The gas pressure in the crack at the end of the stage is reduced because of the crack swelling-up, as compared to the initial formational pressure. The gas pressure obeys the gas law. If the coefficient of stress concentration exceeds the modulus of cohesion despite the reduced gas pressure in the crack at the end of the stage, the crack seems to penetrate the bed instantaneously. In [12], a similar phenomenon, namely, the slip-stick along the boundary of grains, have been discussed. Actually, it should be taken into account [13] that the volume of a crack increases as the crack propagates. So, the pressure of a gas with constant amount is reduced. That is why the stepwise growth of a crack is restricted by the size, where Griffith's inequality is transformed into the equality. This is the mechanism of a known phenomenon called crack burst [14]. In the presented work, the intervals of the control parameters, where the crack burst occurs, have been found. After the burst, a relatively slow period of the crack growth starts. It is called the filtration stage and is determined by the fact that the gas pressure in the crack after the termination of the impact stage becomes and stays less than the formational pressure of the gas in the environment of the crack. Thus, a thermodynamic force, i.e., a gradient of the chemical potential of methane that makes the gas to flow along the filtration channels from the coal/rock to the crack cavity, is generated [15]. Though the gas fills the crack, the gas pressure in the crack is reduced because of the increasing crack volume in the course of the crack growth. In addition, the gas pressure is dropped down because of the gas discharge by the filtration toward the mined-out space. The rate of crack growth at the filtration stage is controlled by the permeability and non-uniformity of the bed. For the first time, the presented work reports a quantitative description of the filtration stage of the crack growth, which is based on the derivation and solution of adequate filtration equations supplemented by the assumption about that the Griffith critical relation between the coefficient of stress concentration and the modulus of cohesion is valid at any given time during this stage. A practically important result is the estimation of the time of the crack penetration through a bed. At representative values of the control parameters (formational pressure, initial crack size, cavitation, bed permeability, and surface energy of coal/rock), the rate of growth of the main crack is about one meter per a minute. In general, in the present work, the kinetic theory of the fracture of gas-containing materials is illustrated by the burst of the edge of a coal/rock bed by the natural gas-filled cracks. The processes paving the way and initiating the instantaneous outbursts of coal, rock, and gas in the course of blasting are discussed. The work does not deal with the modern methods of computer modeling [16]. A combination of these methods with the classical analysis of the physics and mechanics of fracture will lead to important practical results.

\section{Theoretical Modeling}

\subsection{Shock stage evolution of cracks}

In an undisturbed gas-saturated bed, the cracks are under stresses determined by the rock pressure and the formational pressure $P_{0}$ of the gas present in the cavities of cracks. Despite the bursting effect of intracavitary gas pressure, the cracks do not develop, 
because they are pressed by compression stresses. In the course of mining work, the stresses affecting the coal bed are redistributed (we consider a bed of a flat dip for the sake of definiteness). The rock pressure $\sigma_{\text {II }}$ (see Fig. 1) becomes inhomogeneous (abutment pressure). The stresses normal to the exposed surface vanish. The loading-out of the bed occurs with respect to this component of stresses. These stresses are equal to zero on the very exposed surface. The stresses $\sigma_{\perp}$ increase with the distance from the surface and achieve the maximum $\sigma_{m}$ at the distances about a few thicknesses of the bed $h$. That is why the loading-out is characterized by the difference $\sigma_{m}-\sigma_{\perp}$.

After the loading-out, the process of destruction of the material can start due to the development of cracks in a plane parallel to the exposed surface (see Fig. 1). The cracks of another orientation are still suppressed by the rock pressure $[17,18]$.

Let us consider one of the cracks of a selected orientation. We use a two-dimensional model that simplifies the calculations without any loss of similarity of the results.

In the strict sense, we should consider an assembly or a system of cracks. Instead, only one main crack is described, and the rest of pores and cracks modify the stress fields in a vicinity of the main crack, being a reservoir of the gas infiltrating to the cavity of the crack. This approach is a well-known mean-field approximation.

The crack volume is determined by the volume of the original cavity and the stresses operating at the edges. The solution of a classical problem of elasticity theory yields the crack volume (substituted by the cross-section area in the two-dimensional case) in the form

$V=V_{c}+\frac{\sigma}{B} L^{2}$

where $V_{c}$ is the volume of the original cavity, $B$ is the modulus of elasticity of the material, $L$ is the crack length, $\sigma$ are the stresses at the edges. In an undisturbed bed, $\sigma$ consists of two terms. These are the compressing stresses $\sigma_{m}$ and overburden gas pressure. Thus, the volume of a crack in the undisturbed bed is equal to

$V_{0}=V_{c}-\frac{\sigma_{m}-P_{0}}{B} L_{0}^{2}$

where $L_{0}$ is the initial length of the crack. In a declining bed, i.e., in a loaded-out one, $\sigma=-\sigma_{\perp}+P_{1}$,

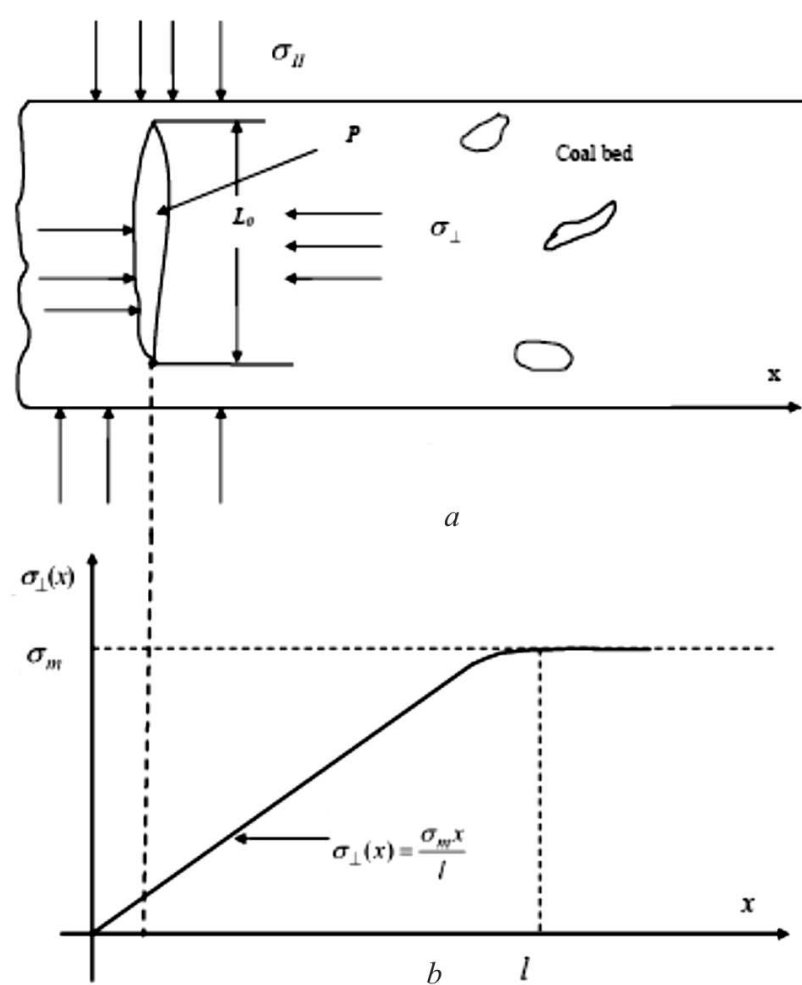

Fig. 1. Scheme of the crack location in a gas-saturated coal bed $(a)$ and the distribution of horizontal stresses along the bed $(b)$

because the gas pressure in the crack cavity decreases from $P_{0}$ to $P_{1}$ due to an increase in the crack volume up to

$V_{1}=V_{c}-\frac{\sigma_{\perp}-P_{1}}{B} L_{0}^{2}$

It follows from (3) and (2) that the crack volume after the loading-out is

$V_{1}=V_{0}+\frac{\sigma_{m}-\sigma_{\perp}-P_{0}+P_{1}}{B} L_{0}^{2}$.

The crack length remains the same in the course of the bed unloading. In practice [1], the gas pressure is usually in fraction of the rock pressure. Thus, the pressure difference $P_{0}-P_{1}$ can be ignored, as compared to the unloading $\sigma_{m}-\sigma_{\perp}$. As a result, the change of the crack volume after the loading-out does not depend on the pressure of a gas in the crack:

$V_{1}=V_{0}+\frac{\sigma_{m}-\sigma_{\perp}}{B} L_{0}^{2}=V_{0}\left[1+\frac{\sigma_{m}-\sigma_{\perp}}{B} \frac{L_{0}^{2}}{V_{0}}\right]$. 
The gap of a crack $z_{0}$ is defined as

$z_{0} \equiv \frac{V_{0}}{L_{0}}$.

A dimensionless parameter is

$a \equiv \frac{\sigma_{m}-\sigma_{\perp}}{B} \frac{L_{0}}{z_{0}}$.

Thus,

$V_{1}=V_{0}(1+a)=V_{0}\left[1+\frac{\sigma_{m}-\sigma_{\perp}}{B} \frac{L_{0}}{z_{0}}\right]$.

The parameter $a$ is the product of a small parameter $V_{1}=\frac{\sigma_{m}-\sigma_{\perp}}{B}$ and a large parameter $V_{1}=\frac{L_{0}}{z_{0}}$, i.e., the relative loading-out and the ratio of the crack length (cross-section) to the gap, respectively. For instance, when

$\sigma_{m}=2 \times 10^{7} \mathrm{~Pa}$,

$B=10^{9} \mathrm{~Pa}$,

$L_{0}=10 \mathrm{~cm}$,

$z_{0}=1 \mathrm{~mm}$,

we get $a=2$. It is obvious that the value of $a$ can vary in a wide range from $a \ll 1$ to $a \gg 1$. Up to now, the bed unloading was discussed irrespectively of the rate of unloading. We suggest further that the loading-out was momentary as a result of the explosion, for example. As the time period is small, the amount of a gas in the cavity of the original crack is not changed. According to the equation of state for the ideal gas at a constant temperature, we have

$P_{1} V_{1}=P_{0} V_{0}$

Employing (8), we obtain the gas pressure in the crack after the unloading:

$P_{1}=\frac{P_{0}}{1+a}$,

i.e., the pressure is reduced immediately after the loading-out. Now, we pass directly to the problem of crack development. As is known (7), (9), Griffith found that the crack size (in our case, $L$ ) increases, when the coefficient of stress concentration at the tip of a crack becomes higher than the modulus of cohesion $M_{c}$, which is determined by the forces of interaction of crack edges at its tip. Within the twodimensional model, the coefficient of concentration is $\frac{\pi}{2} \sigma \sqrt{L}$, where $\sigma$ is the stress at the crack edges. In the considered case, $\sigma=P_{1}-\sigma_{\perp}$ immediately after the unloading. So, according to Griffith, the crack does not propagate, when

$\frac{\pi}{2}\left(P_{1}-\sigma_{\perp}\right) \sqrt{L_{0}}<M_{c}$.

In a coal massive,

$M_{0} \equiv \frac{\pi}{2} P_{0} \sqrt{L_{0}}<M_{c}$.

Since $P_{1}<P_{0}(10)$, inequality (11) will be valid conservatively, i.e., the crack will not propagate along its length, and the process will be restricted by the crack swelling and an increase in the gap. So, inequality (12) is a sufficient condition of outburst safety. Using the representative values of parameters entering into (12), namely,

$P_{o}=10^{6} \mathrm{~Pa}$,

$B=4 \times 10^{9} \mathrm{~Pa}$,

$L_{0}=10^{-2} \mathrm{~m}$,

$M_{c} \approx \sqrt{B \chi}$,

$\chi=10 \mathrm{~Pa} \cdot \mathrm{m}$,

being the specific surface energy of coal, we see that inequality (12) is valid. However after a small increase in the rock pressure or the length of the main crack, inequality (12) fails, and the inverse inequality becomes valid instead of (12):

$M_{0} \equiv \frac{\pi}{2} P_{0} \sqrt{L_{0}}>M_{c}$.

This fact does not mean that the fracture starts obligatorily. Two possible scenarios can proceed. 1) If $\frac{\pi}{2}\left(P_{1}-\sigma_{\perp}\right) \sqrt{L_{0}}<M_{c}$, the crack will not propagate immediately after the unloading, it will just swell. Further, due to a gas flow determined by the appeared pressure gradient $P_{0}-P_{1}$, the inner gas pressure can reach a critical limit. Griffith's inequality (11) will be transformed into the equality, and the crack length will grow. 2) If $\frac{\pi}{2}\left(P_{1}-\sigma_{\perp}\right) \sqrt{L_{0}}>M_{c}$, a jump increase in the cross-section of the crack up to $L_{2}$ and a related decrease in the pressure down to $P_{2}$ occur. So, Griffith's equality

$\frac{\pi}{2}\left(P_{2}-\sigma_{\perp}\right) \sqrt{L_{2}}=M_{c}$ 
becomes valid, and the crack will rise from $L_{0}$ to $L_{2}$. To find $L_{2}$, we note that the primary swelling and the succeeding expulsion of the crack are almost momentary, taking about $10^{-5} \mathrm{~s}$. So, the amount of a gas in the crack remains the same. We have

$P_{2} V_{2}=P_{0} V_{0}$

Similar to (5), the crack volume after the swelling and expulsion is equal to

$V_{2}=V_{0}\left[1+a \frac{L_{2}^{2}}{L_{0}^{2}}\right]$

So, we have three equations (14), (15), and (16) with three unknown variables, $P_{2}, V_{2}$, and $L_{2}$. For the sake of simplicity, we consider the maximum unloading, when $\sigma_{\perp}=0$, and unloading is $\sigma_{m}-\sigma_{\perp}=\sigma_{m}$. Let us introduce $\lambda \equiv \sqrt{\frac{L_{2}}{L_{0}}}$. The method of elimination of the unknowns yields

$\frac{\lambda}{1+a \lambda^{4}}=\frac{M_{c}}{M_{0}}$.

The graphical solution of (17) is presented in Fig. 2.

Figure 2 demonstrates that Eq. (17) has either two or no real roots. The first case is realized, if the inequality

$a<\frac{M_{0}}{M_{c}}-1, \quad \frac{\sigma_{m}-\sigma_{\perp}}{B} \frac{L_{0}}{z_{0}}<\frac{M_{0}}{M_{c}}-1$

is valid. The root with $\lambda>1$, i.e., $\lambda_{p}$, should be selected among the two roots (Fig. 2), because the crack never collapses, and the size can be only increased. The crack is chambered, i.e., the size increases very rapidly from $L_{0}$ to $\lambda_{p}^{2} L_{0}$. In this sense, it is the impact stage of crack development. If the unloading is maximal and equals $\sigma_{m}$, the same criterion (18) is easily derived from the inequality $\frac{\pi}{2} P_{1} \sqrt{L_{0}}>M_{c}$. To satisfy the criterion of crack chambering (18), the validity of Griffith's criterion $M_{0}>M_{c}$ is necessary, but insufficient for an undisturbed bed. Moreover, for an unloaded bed, the parameter $a$ must be small enough. This situation is associated with a high initial gap of the crack and a low level of maximum unloading, i.e. when the rock pressure is not so high. With increasing the excavation depth, the formational pressure usually increases and facilitates the crack development. At the same time, the unloading is increased as well,

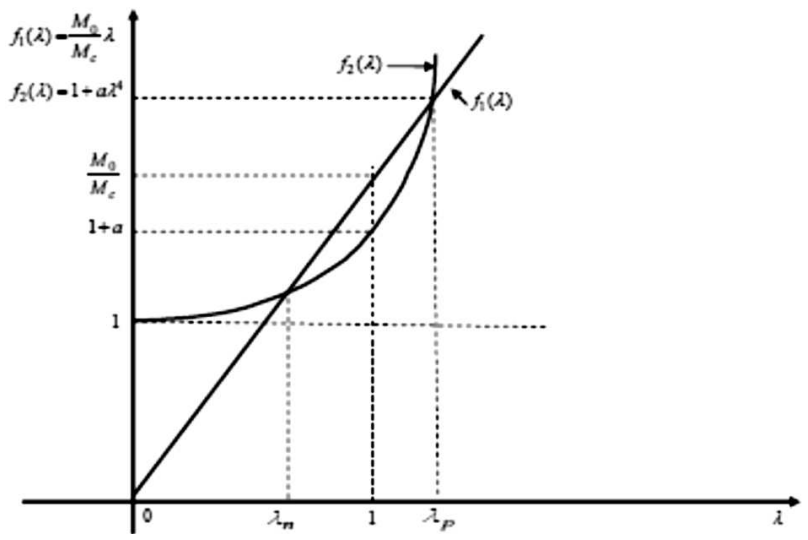

Fig. 2. Graphical solution of Eq. (17)

the crack is expanded, and the gas pressure is reduced. As a result, the possibility of a crack growth decreases. Evidently, there exists an excavation depth of gas-saturated coal beds, which is the most hazardous with respect to the crack growth and outbursts. In summary, it can be stated that the criterion inequality (18) indicating the jump-like growth of a crack is a generalization of Griffith's criterion in the case where the breaking stresses are generated by a gas contained in the crack cavity. As for the relative increment of the crack size, it increases with the value of $\frac{M_{0}}{M_{c}}$ : when the formational pressure increases, the modulus of cohesion decreases, the gap increases, and the unloading decreases. If a bed or a rock has a system of parallel cracks at a comparatively small distance between them, and the chambering of the crack, which is the nearest to the surface, occurs, the instantaneous loading-out of a material in a vicinity of the neighbor crack happens, and this crack is expanded. Further, this process will obey the domino effect: the sudden outburst of coal, rock, and gas is realized by the layerby-layer breakage by $[2,6]$. The breakage attenuation is caused by the destruction of the structure of a system of parallel cracks, for instance. The distance between the cracks associated with the layerby-layer breakage can be estimated, by using inequality (11). In place of $\sigma_{\perp}$, we should take the value of compressing stresses in a crack at the distance $x$ from the surface, where $x$ is the sought distance between the cracks. It is quite correct to suppose that

$\sigma_{\perp}(x)=\sigma_{m} \frac{x}{h}$ 
where $h$ is about the bed thickness by order. In addition, if we assume that $P_{1} \approx P_{0}$, we get the inequality

$\frac{\sigma_{m}}{P_{0}} \frac{x}{h}<1-\frac{M_{c}}{M_{0}}$.

As is seen from the estimations listed above, for $L_{0} \approx 20 \mathrm{~cm}, \frac{\sigma_{m}}{P_{0}} \approx 4$ and $\frac{M_{c}}{M_{0}} \approx 0.4, x$ is assessed as

$x<0.1 h$.

In other words, in a bed $1 \mathrm{~m}$ in thickness, the distance between the cracks associated with the layer-bylayer breakage should be less than $10 \mathrm{~cm}$. Inequality (20) can be considered as a criterion of outburst generation.

\subsection{Filtration stage of the crack evolution}

Now, we proceed with the crack behavior after the swelling and/or chambering. Because of an instantaneous increase in the crack volume, the gas pressure in the crack drops rapidly. Thus, there appears a driving force for a gas flow to the crack cavity from the surrounding filtration volume. In order to establish the laws governing this process in the strict sense, a diffusion-like equation (Darcy's equation for the filtration) should be solved with the related initial and boundary conditions. The initial condition is given by the pressures at the initial time moment both in crack cavities and the environment. As the boundary condition, the equality of gas pressures at both edges of a crack is employed. It is found that if the crack size is large as compared to the "diffusion" length, the so-called impedance relation of the theory of parabolic equations can be applied to our problem in the form

$\frac{d N(t)}{d t}=\frac{2 \gamma L(t) \sqrt{D_{f}}}{\sqrt{\pi} T} \frac{d}{d t} \int_{o}^{t} \frac{P_{e}(\tau)-P(\tau)}{\sqrt{t-\tau}} d \tau$.

Here, $N(t)$ is the number of gas molecules within the crack cavity, $D_{f}$ is the coefficient of gas filtration, $P(t)$ is the unknown gas pressure in the crack, $t$ is the time, $\gamma$ is the void factor of the solid mass, i.e., the ratio of the volume of cavities filled by a gas to the volume of the solid, factor 2 emerges because of the presence of two crack edges, $P_{e}(t)$ is the gas pressure in the environment of the crack, and $T$ is the absolute temperature. Relation (22) should be supplemented with the ideal gas law at an arbitrary time for an isothermal process ( $T$ is the absolute temperature in the energetic units):

$P(t) V(t)=N(t) T$

and the formula for the crack volume is

$V(t)=V_{0}\left[1+a \frac{L_{2}^{2}}{L_{0}^{2}}\right]$.

In the simplest case where the crack length is constant $\left(L(t)=L_{0}\right)$, the written equations allow us to explicitly estimate the dynamics of the gas pressure in a crack cavity. As a result, we have

$\frac{d P(t)}{d t}=\frac{2 \gamma L_{0} \sqrt{D_{f}}}{\sqrt{\pi} V_{0}(1+a)} \frac{d}{d t} \int_{o}^{t} \frac{P_{e}(\tau)-P(\tau)}{\sqrt{t-\tau}} d \tau$.

From whence, we get

$P(t)=P_{1}+\frac{2 \gamma L_{0} \sqrt{D_{f}}}{\sqrt{\pi} V_{0}(1+a)} \int_{o}^{t} \frac{P_{e}(\tau)-P(\tau)}{\sqrt{t-\tau}} d \tau$,

where $P_{1}$ is the gas pressure in the crack at the initial time moment derived from (10). The time of the gas filtration to the crack can be introduced as

$t_{f}^{(1)} \equiv \frac{\pi(1+a)^{2} z_{0}^{2}}{4 \gamma^{2} D_{f}}$.

It follows from (27) that the "diffusion" length discussed above is equal by order to $(1+a) z_{0} / \gamma$. The introduction of the dimensionless time with $t_{f}$ yields an equation that does not contain any parameter except $P_{e}(t)$. We write this equation, where the time normalized to $t_{f}$ is designated by the same symbol as the dimensional time, as

$P(t)=P_{1}+\int_{o}^{t} \frac{P_{e}(\tau)-P(\tau)}{\sqrt{t-\tau}} d \tau$.

If $P_{e}(t)=P_{0}=$ const, the equation can be solved in the known tabulated functions:

$P(t)=\left(P_{1}-P_{0}\right)(1-\Phi(\sqrt{\pi t})) e^{\pi t}+P_{0}$,

where $\Phi(x)$ is the probability integral. It follows from (29) that, at small times $(t \ll 1)$, the pressure increases by a square-root law, $P(t) \approx P_{1}+2\left(P_{e}-\right.$

ISSN 2071-0194. Ukr. J. Phys. 2019. Vol. 64, No. 3 
$\left.-P_{1}\right) \sqrt{t}$. When the time is large, $t \gg 1$, the pressure approaches $P_{0}$ from below as the inverse square root of the time. As the pressure $P_{1}$ is below the threshold of Griffith' crack initiation, and $P_{0}$ is above this threshold, there comes a time when the current pressure $P_{2}$ provides the crack growth. The duration of the corresponding preparation stage is about $t_{f}^{(1)}$, as seen from (29). The duration is strongly dependent on the crack gap (proportional to $z_{2}^{0}$ ). It increases, as the void factor and filtration permeability of coal decrease, and the level of unloading increases (through the parameter $a$ ). The value of $t_{f}^{(1)}$ can be roughly estimated to be about several minutes, and it can be interpreted as the outburst initiation time in the case where the suitable conditions are present. In the general case, the external gas pressure $P_{e}(t)$ is reduced in time because of the gas release through the face to the entry. That is why (29) is valid, when the time of the outside gas release is much more than $t_{f}^{(1)}$. This fact is confirmed by calculations based on (28), when the decrease in the external pressure is modeled by a linear function of time:

$P_{c}(t)=P_{0}(1-\gamma t)$,

where $\gamma$ is the inverse time of the gas release from the crack environment.

Figure 3 demonstrates that, at $t_{f} \ll 1$, a change of the pressure dynamics $P(t)$ is insignificant, as compared to (29). The assessment of the time of the gas release from the zone of oriented cracks [9] gives $\frac{l_{0}^{2}}{D_{f}}$, $l_{0}$ is about the distance from the face to the place with the abutment pressure peak, and $l_{0} 3-5 \mathrm{~m}$.

At $D_{f} \approx 10^{-6} \mathrm{~m}^{2} / \mathrm{s}$, this time is about a day, being much longer than $t_{f}$. This fact means that if the inequality $M_{0}>M_{c}$ is valid, and if the total unloading occurs, the oriented main crack will grow despite an increase in the volume because of the loading-out and the related drop in the pressure inside. Only a definite delay $t_{f}^{(1)}$ will be observed, being determined by the gas filtration from the environment to the crack cavity.

\subsection{Gas inleakage to the moving crack}

Hereupon, a new stage of evolution, which is controlled by the gas inleakage to the moving crack, starts with $L=L(t)$. We suppose that, at this stage at an arbitrary time, Griffith's equality

$\frac{\pi}{2} P(t) \sqrt{L(t)}=M_{c}$

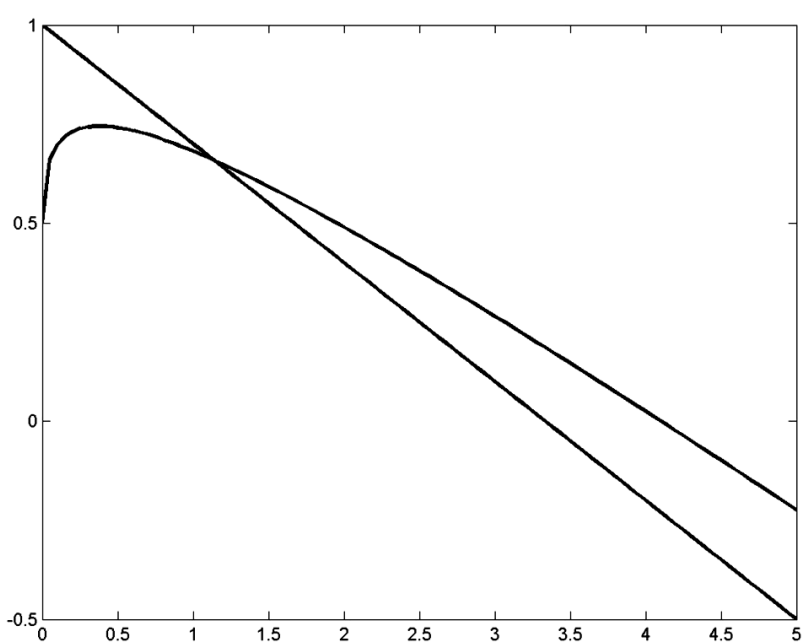

Fig. 3. Numerical solution of Eq. (28) with regard for (30)

is valid. Thus, relations (22), (23), and (24) yield

$\frac{1}{L(t)} \frac{d}{d t}\left[P(t) V_{0}\left(1+\frac{a L^{2}(t)}{L_{0}^{2}}\right)\right]=$

$=\frac{2 \gamma \sqrt{D_{f}}}{\sqrt{\pi}} \frac{d}{d t} \int_{0}^{t} \frac{P_{e}(\tau)-P(\tau)}{\sqrt{t-\tau}} d \tau$.

As before, it is quite warranted that $P_{e}(t)=P_{0}$. In this situation, the pressure should be measured in units of $P_{0}$, i.e., $p(t) \equiv \frac{P(t)}{P_{0}}$, and the time should be measured in units of

$t_{f}^{(2)}=\frac{\pi z_{0}^{2}}{4 \gamma^{2} D_{f}}\left(\frac{M_{0}}{M_{c}}\right)^{2}$

In view of (31), we get the intermediate equation

$p^{2}(t) \frac{d}{d t}\left[p(t)+\left(1+\frac{a M_{c}^{4}}{M_{0}^{4} p^{4}(t)}\right)^{4}\right]=\frac{d}{d t} \int_{0}^{t} \frac{1-p(\tau)}{\sqrt{t-\tau}} d \tau$.

As before, the dimensionless time $t / t_{f}^{(2)}$ inherits the same designation as the dimensional one. Further transformations are aimed at the elimination of derivatives in Eq. (34). The result is as follows:

$\frac{1}{3}\left(p^{3}(t)-p_{2}^{3}\right)-a\left(\frac{M_{c}}{M_{0}}\right)^{4}\left(\frac{1}{p(t)}-\frac{1}{p_{2}}\right)=\int_{0}^{t} \frac{1-p(\tau)}{\sqrt{t-\tau}} d \tau$

where $p_{2}$ is the pressure at the final of the preceding stage. It can be the pressure after the chambering derived from the system of (14)-(16) (case 2); it can be

213 


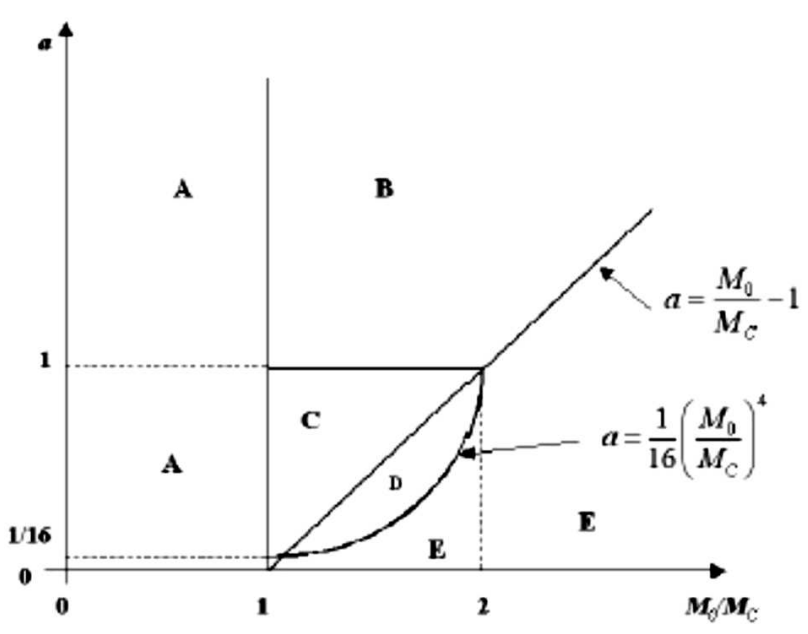

Fig. 4. Diagram of the scenarios of crack evolution

also the pressure after the crack swelling in the course of filtration (case 1). Since the crack length can increase only, it follows from (31) that the gas pressure in the crack can only decrease at this stage. Now, we consider the consequences of this statement and find the asymptotics of solution (35) for early and late times. At $t=0, p(0)=p_{2}$. With regard for the pressure increment $\Delta p$ at $t \ll 1$, we obtain

$$
\left(p_{2}^{2}-\frac{a M_{c}^{4}}{M_{0}^{4} p_{2}^{2}}\right) \Delta p=2\left(1-p_{2}\right) \sqrt{t} .
$$

In other words, a very fast (proportional to $\sqrt{t}$ ) pressure change takes place at early stages, as well as a fast increase in the crack length in accordance with (31). As mentioned earlier, $\Delta p<0$, and a positive quantity is on the right-hand side of (36). Then the following inequality should be valid:

$p_{2}^{4}<a\left(\frac{M_{c}}{M_{0}}\right)^{4}$, i.e. $p_{2}<a^{1 / 4} \frac{M_{c}}{M_{0}}$.

The criterial inequality (37) means that if it is satisfied, the considered stage of crack evolution characterized by its elongation and a drop in the gas pressure is realized. If the inverse inequality takes place, the instantaneous fracture by Griffith occurs. Now, we should find the laws of increase in the crack length and decrease in the gas pressure for late times $(t \gg 1)$. For this purpose, only one term with $p(t)$ involved reciprocally should be left on the left-hand side of Eq. (38). Suppose that $p(\tau)=0$ on the right-hand side of the equation, we obtain

$p(t) \approx\left(\frac{M_{c}}{M_{0}}\right)^{4} \frac{2 a}{\sqrt{t}}$.

According to (37) with the normalization of time by $t_{f}^{2}$, we have

$L(t) \equiv V_{c} t \approx L_{0} \frac{M_{0}^{6}}{4 a^{2} M_{c}^{6}} \frac{t}{t_{f}^{(2)}}$,

i.e., the crack moves with constant velocity $V_{c}$. We estimated that $V_{c}$ is about a meter per minute for standard quantities entering (39).

\section{Results and Discussion}

Now, we summarize the results of the above study of a crack evolution after the instantaneous unloading. First of all, if $\frac{\pi}{2} P_{0} \sqrt{L_{0}} \equiv M_{0}<M_{c}$, the crack will not grow, it will slightly swell, the pressure will be reduced to $P_{1}=\frac{P_{0}}{1+a}$, and then a gas will fill the crack. Neglecting the gas release outward the bed, the pressure within the crack will regain the value of $P_{0}$ due to the gas inleakage. When $M_{0}>M_{c}$, different variants of crack evolution are possible.

1. If $a>\frac{M_{0}}{M_{c}}-1$, as before, the gas inleakage will immediately start after the loading-out and the pressure decrease, which will last up to the point of validity of Griffith's equality $p_{2} \equiv \frac{P_{2}}{P_{0}}=\frac{M_{c}}{M_{0}}$.

a) Additionally, if inequality (37) is valid, i.e., $a>$ $>1$, the inleakage will proceed together with an increase in the crack size until the breakage.

b) When $a<1$, i.e. inequality (37) is not satisfied, the breakage will happen immediately after the primary inleakage.

2. If $a<\frac{M_{0}}{M_{c}}-1$, the problem is reduced to the analysis of the system of equalities $p \lambda=\frac{M_{c}}{M_{0}}, \frac{\lambda}{1+a \lambda^{4}}=$ $=\frac{M_{c}}{M_{0}}$ and inequality (37). The results of the analysis are: When $a>\frac{1}{16}\left(\frac{M_{0}}{M_{c}}\right)^{4}$, the crack chambers immediately after the loading-out, the crack size increases from $L_{0}$ to $L_{2}$, and the pressure decreases abruptly to $P_{2}$ (17). Further, the crack grows up to the material breakage, and the pressure drops to zero according to (38) and (39), despite the gas inleakage.

b) If $a<\frac{1}{16}\left(\frac{M_{0}}{M_{c}}\right)^{4}$, the crack spreads instantly through the bed. The diagram illustrating different scenarios of crack growth depending on the parameters $\frac{M_{0}}{M_{c}}$ and $a$ is presented in Fig. 4 .

ISSN 2071-0194. Ukr. J. Phys. 2019. Vol. 64, No. 3 
The regions of the diagram are designated as follows: A - the cracks do not grow; B - the cracks grow in two stages due to the gas infiltration to the cavity; the first and second stages are associated with the swelling and the crack growth, respectively; $\mathrm{C}-$ the instantaneous propagation of cracks after the gas inleakage; D - the chambering followed by the propagation at the rate of filtration; $\mathrm{E}$ - the instantaneous propagation without filtration.

The diagram in Fig. 4 is constructed for the case of total loading-out of a part of the bed, where the crack is located. The diagram should be corrected in the case of partial unloading, but the trends of the parameters $a$ and $\frac{M_{0}}{M_{c}}$ are conserved. However, it should be kept in mind that the unloading involves not only the parameter $a$, but also Griffith's criterion. In addition, when considering the filtration, the exhaustion of a coal matrix with respect to a gas due to a great number of cracks should be taken into account.

\section{Conclusions}

We have established that the crack growth in gassaturated porous compressed materials (e.g., coals, sandstones, shales, some of the reactor materials) after the instantaneous loading-out (decompression) occurs in two stages. At the first impact stage, the crack volume is instantaneously increased at the rate of expansion of the gap. The material swells out. Then, at a certain initial gas pressure, under the decompression, for the crack size, modulus of cohesion, and modulus of elasticity, which have been evaluated above, the crack can burst, and the crack length can increase by several times. Griffith's criterion has been modified to be applied to the considered situation. The kinetic equations describing the filtration stage of crack evolution have been derived and solved. The filtration stage is controlled by the gas inleakage from the environment to the crack cavity. The rate of crack growth at this stage has been found. The developed theory has been applied to the estimation of the parameters determining the characteristics of the processes that precede instantaneous outbursts of coal, rock, and gas in the course of the blasting of coal deposits. The estimative diagram showing the outburst hazard of the edge of a coal bed has been constructed.
1. A.D. Alexeev. Physics of Coal and Mining Processes (CRC Press, 2011).

2. S.A. Khristianovich, R.L. Salganik. Sudden Outbursts of Coal and Gas, Stresses and Strains. Preprint 153 (Inst. Probl. Mech. of the AS of the USSR, 1980) (in Russian).

3. G.A. Shevelev. Dynamics of Coal, Rock, and Gas Outbursts (Naukova Dumka, 1989) (in Russian).

4. X.G. Zhao, M. Cai, J. Wang, P.F. Li, L.K. Ma. Objective determination of crack initiation stress of brittle rocks under compression using AE measurement. Rock Mechanics and Rock Engineering 48, Iss. 6, 2473 (2015).

5. A.D. Alexeev, E.P. Feldman, T.A. Vasilenko. Kinetics of methane desorption from coal nano- and mesostructures. Energy and Fuels 24, 4375 (2010).

6. S.A. Khristianovich, R.L. Salganik. Outburst-Prone Situation, Crushing, Outburst Wave. Preprint 152 (Inst. Probl. Mech. of the AS of the USSR, 1980) (in Russian).

7. A.A. Griffith. The phenomena of rupture and flow in solids. Phil. Trans. Royal Society of London A 221, 163 (1921).

8. T.L. Anderson. Fracture Mechanics. Fundamental and Appications (CRC Press, 1995).

9. G.I. Barenblatt. Mathematical theory of equilibrium cracks appearing under brittle fracture. J. Appl. Mech. Tech. Phys. 4, 3 (1961).

10. H. Zhi-ru, J. Yao-dong, Z. Yi-xin, G. Qing-ji. Study of crack propagation of bump-prone coal sample. Procedia Earth and Planetary Sci. 1, 471 (2009).

11. Li Zhenlei, Dou Linming, Cai Wu et al. Investigation and analysis of the rock burst mechanism induced within fault-pillars. Int. J. Rock Mech. Mining Sci. 70, 192 (2014).

12. L.S. Metlov, M.M. Myshlyaev, A.V. Khomenko, I.A. Lyashenko. Slip model for grain boundaries in the course of deformation. Tech. Phys. Lett. 38, 11 (2012).

13. E.P. Feldman, V.M. Yurchenko, V.A. Streltsov, E.V. Volodarskaya. Precritical growth of cracks in gas-containing materials. Sov. Phys. Solid State 34, 618 (1992).

14. B.B. Beamish, P.J. Crosdale. Instantaneous outbursts in underground coal mines: An overview and association with coal type. Int. J. Coal Geology 35, 27 (1998).

15. A.D. Alekseev, E.P. Feldman. Non-Equilibrium Thermodynamics and Outburst Hazard of a Coal Bed. Ukr. J. Phys. 57, 619 (2012).

16. S. Xue, Y.C. Wang, J. Xie, G. Wang. A coupled approach to simulate initiation of outbursts of coal and gas - Model development. Int. J. Coal Geol. 86, 222 (2011).

17. S. Wang, D. Elsworth, J. Liu. Rapid decompression and desorption induced energetic failure in coal. Int. J. Rock Mech. Geotech Eng. 7, 345 (2015).

18. S. Wisetsaen, C. Walsri, K. Fuenkajorn. Effects of loading rate and temperature on tensile strength and deformation of rock salt. Int. J. Rock Mech. Mining Sci. 73, 10 (2015).

Received 26.01.18 
Е.П. Фелъдман, Н.О. Калугіна, Т.М. Мелъник

КІНЕТИЧНА ТЕОРІЯ РУЙНУВАННЯ

ВУГІЛЬНОЇ/ПОРОДНОЇ КРАЙОВОЇ ДІЛЯНКИ

ГАЗОНАПОВНЕНИМИ ТРІЩИНАМИ. РАПТОВЕ РОЗВАНТАЖЕННЯ.

$\mathrm{P}$ е $з$ ю м е

Кінетична теорія руйнування крихких матеріалів застосована до дослідження докритичного і критичного зростання тріщин у газонасичених гірських породах. У таких матеріалах важливу роль відіграє фільтрація газу з оточення в порожнину зростаючої тріщини. Явний облік цього чинника в поєднанні з динамікою напруженого стану пласта до- зволив, в припущенні, що виконується критерій Гріффітса, встановити швидкість росту магістральної тріщини. Встановлено, що після раптового розвантаження пласта при його відпрацюванні, тріщини певних розмірів і орієнтації негайно "вистрілюють", після чого їх подальше зростання відбувається в міру надходження газу всередину тріщин. Дана оцінка часу фільтраційного зростання тріщин. Знайдено області зміни керуючих параметрів (пластового тиску газу, розмірів тріщин, надлишкового тиску, поверхневої енергії вугілля/породи, модуля пружності), всередині яких спонтанне руйнування пласта стає можливим. Це відкриває шлях до прогнозування раптових викидів вугілля, породи і газу. 